\title{
Una visión actual de la contratación atípica a la luz del código civil cubano. \\ Especial referencia a los contratos con sujetos vulnerables
}

Anabel Puentes Gómez

Universidad de La Habana, Cuba

anabelpuentes@lex.uh.cu

Fecha de recibido: julio 2017 / Fecha de aprobación: noviembre 2017

\section{Resumen}

Este trabajo indaga en cómo a treinta años de la promulgación del Código Civil Cubano, el análisis de la contratación atípica en contraste con la realidad imperante resulta todo un reto. Conjugar libertades contractuales, con normas interpretativas y atipicidades, nos lleva a mirar el Derecho Civil de forma sistémica desde sus principios generales hasta el mercado, los actores de hoy en la contratación y los que necesitan incursionar en el mundo del negocio y las relaciones jurídicas obligatorias. Es por ello que en un primer momento se trata de engarzar las tendencias interpretativas con los caracteres y fundamentos de los contratos atípicos en función de los retos que se presentan en relación con la figura. Posteriormente se analiza como la contratación para los sujetos vulnerables como el mandato de protección futura y el contrato de alimentos devienen en alternativas para sujetos dependientes, de manera que por su naturaleza y causa negocial, tengan reglas de interpretación contractual diferenciadas.

\section{Palabras clave}

Contratos atípicos / vulnerabilidad / dependencia / interpretación / libertad contractual

\section{Tabla de contenido}

I. A modo de introducción. 2. Acercamiento al escenario del Derecho Contractual Moderno. En busca de nuevos bríos. 3. Libertad Contractual y contratación atípica 4. La Interpretación, el solidarismo y la tipicidad social. Incidencias para los contratos atípicos y sus retos. 5 La contratación y la protección a los sujetos vulnerables. 5.I El mandato de protección futura. 5.2 El contrato de alimentos. Nuevas perspectivas para la realidad cubana. 6. A modo de cierre.

\section{A modo de introducción}

Comentar el universo de la codificación civil cubana ha despertado en no pocos encuentros, ignorancia, olvido y hasta desprecio. Su abordaje desde los pensamientos más serios y de avanzada hasta los análisis críticos y voraces, nos direcciona a enfocarnos en un Código Civil visualizado desde los operadores del Derecho, en conjunción con una realidad imperante en extremo demoledora. 30 años más tarde de la promulgación 
de una obra entretejida con tino y avidez, nos tropezamos con algunos que evocan un quehacer habitual que les enfrenta a su contenido, a encontronazos o conflictos con normas especiales, al no tener qué hacer cuando resultan parcas algunas materias. La trascendencia del Código Civil Cubano nos conduce a recordar que las normas son conceptos, ideas, consideraciones enmarcadas en un determinado momento histórico, de modo que cambia la significación de la ley según la evolución que marca la historia.

El componente referido a las obligaciones y contratos del Código Civil Cubano, independientemente del carácter general y abstracto que rige toda obra codificadora, resulta lacónico sobre todo cuando nos encontramos hoy con una contratación que debe ser dirigida al reconocimiento de principios como la autonomía y la libertad contractual; a la existencia de una dinámica en la contratación donde las personas naturales y jurídicas, no recurren necesariamente a las figuras pre establecidas por la ley para satisfacer sus respectivos intereses. Por otra parte, la materia contractual vino a matizarse con la incorporación del Decreto Ley 304 y Decreto 310 sobre la contratación económica, que incorpora las figuras más flamantes del Derecho de Contratos, teniendo como vanguardia la afiliación de los principios generales sobre la materia que habían quedado vacantes en el Código Civil.

Una aparición normativa sustentada en realidades globales de obligada inserción y que nos demanda una transformación legislativa al respecto, que busque cambios de paradigmas en torno a la concepción del contrato.

"El mercado y el comercio se han visto en la necesidad de buscar alternativas en una economía globalizada y de grandes transformaciones que les posibiliten desarrollarse de manera competitiva, rápida y ágil. Por este motivo, las empresas han superado los contratos ortodoxos que muchas veces están desfasados de las necesidades económicas, financieras y jurídicas actuales, y se han creado nuevas modalidades de contratación conocidas como Contratos Innominados en la búsqueda de ser más competitivos, ya que hoy en día estamos inmersos en una economía de mercado globalizada."

Contamos con una premisa: los cambios en los últimos tiempos en la concepción del contrato debe contribuir a que el mismo se convierta en un negocio "por y para el hombre", teniendo en cuenta a los sujetos y otros escenarios los cuales abordaremos con posterioridad. Es por ello que esta investigación indaga en la problemática sobre cómo la inexistencia de un régimen normativo sistémico aplicable a los contratos atípicos, que conjugue libertad contractual y pautas interpretativas particulares que se pongan al servicio de sujetos vulnerables, provoca una desprotección jurídica a los mismos. Intentaremos abordar la problemática de una manera expositiva, de forma que genere cuestionamientos al respecto y conduzca al análisis, alejándonos de soluciones duras y firmes, las cuales resultan complejas en temáticas como la de referencia.

Finalmente abordaremos el contrato de alimentos como un contrato atípico para la realidad cubana y otros países de América Latina, que demanda especial razonamiento

\footnotetext{
96 Ugarte Vega-Centeno, Máximo, "Apuntes sobre los Contratos Atípicos o innominados", en Gestión en el Tercer Milenio, Rev. de Investigación de la Fac. de Ciencias Administrativas, UNMSM, Vol. 13, N²5, Lima, julio 2010, p.20.
} 
como alternativa de protección a algunas personas que pueden configurarse como parte débil dentro de la relación jurídica.

\section{Acercamiento al escenario del Derecho Contractual Moderno. En busca de nuevos bríos}

Para continuar mostrando el escenario actual en que se encuentra la contratación no se puede obviar cómo la dinámica de cambio del Derecho Contractual se constata solo de dirigir una mirada a normativas como las Reglas de Viena sobre venta internacional de mercaderías, el Código Unificado de los Estados Unidos de América, los principios del UNIDROIT y otras normas transformadoras de lo que hasta entonces entendíamos como materia contractual.

Por otra parte, visiones contemporáneas que ajustan el contrato a los tiempos actuales entrelazan el orden normativo con los elementos de la realidad que pretende regular. Interesante resulta la valoración de HERRERA OSORIO cuando argumenta:

“...el contrato dejó de verse exclusivamente como la forma más acabada de la voluntad individual y empezó a analizarse a la luz de la finalidad socioeconómica que inspira cada uno de los tipos negociales, considerando la realidad objetiva de las partes que en él intervienen. Por ello, ha venido perdiendo peso el elemento subjetivo (la intensión), frente al contenido objetivo (visión abstracta), enmarcado dentro de componentes morales que limitan el alcance de las actuaciones particulares. Se justifica entonces, la existencia de obligaciones aún no pactadas, siempre que ellas busquen hacer efectivas el interés negocial de los partícipes, y se morigeró el principio de relatividad de los contratos, situaciones todas explicables por la vuelta sobre el contexto en el que se inserta el contrato." 97

Frente a la necesidad de lograr hoy movilización de activos de forma masiva, la existencia de menores tiempos de contratación, la reducción de costos de transacción y mayor seguridad jurídica, la supresión de la fase de negociación; nos aqueja el pensar al contrato de manera que se reconozca al hombre como centro del mismo.

Los últimos tiempos resaltan la presencia de desigualdades económicas en los sujetos contratantes, lo que provoca que uno de ellos imponga su voluntad sobre el otro, despareciendo así la manifestación libre de la voluntad, existiendo la tendencia a la desaparición del contrato como libre manifestación de voluntades concurrentes -sobre lo cual discrepo- y que ha traído como corolario la protección del contratante débil o vulnerable. Es que dicha protección no deja al margen la autonomía ni olvida la naturaleza privada de esta materia, sino que busca el carácter humanista del Derecho Contractual, donde más que una relación jurídica obligatoria se inquieran mecanismos de humanización en función del negocio.

\footnotetext{
97 HeRRERA OSORIO, Fredy Andrei, "La contratación contemporánea: Ejemplo de la apertura del derecho al contexto" en, Pensamiento Jurídico, No. 33, 2012 en http://revistas.unal.edu.co, consultado 10 de mayo de 2017 , p.227
} 
En palabras del profesor DíEZ PICAZO"9: "la contratación se ha convertido en un mecanismo de interacción social imprescindible en la vida moderna, pero, por lo mismo, su función a través del tiempo ha ido sufriendo alteraciones en relación a la forma de concebirla." Es por ello que en tiempos donde nos preocupamos por los más vulnerables, la concepción contractual y sus tipologías deben ser reelaboradas.

Volviendo a nuestro Código, la posibilidad de contratación más allá de lo típico, fue prevista por el legislador cubano iniciada por su consagración en el artículo 3 I2, en virtud del cual las partes pueden establecer los pactos, cláusulas y condiciones que tengan por conveniente salvo disposición legal en contrario; además del reconocimiento en el precepto 314 de que las relaciones contractuales no comprendidas en ninguno de los tipos contractuales consagrados, se rigen por las normas de los contratos más afines y por los principios y preceptos del Código Civil. Es por ello, que en materia contractual, la dinámica codificadora no se mostró restrictiva en este sentido, sino que admitió otras tipologías, aunque, la analogía pretendida no se logra del todo con los tipos más modernos.

Los nuevos acontecimientos en materia de instrumentos privados y el valor añadido de las nuevas tecnologías, impactan en la tradicional legalidad; y es que el esquema contractual debe seguir constituyendo un instrumento de progreso, independientemente de la tipicidad lograda en las normas jurídicas, y teniendo como cumbre la autonomía de la voluntad. Así lo comentan desde la doctrina argentina al valorar: "En el contrato moderno confluyen elementos que determinan una regulación compleja, en la que las disposiciones de autonomía generadas por las partes se entrecruzan con regulaciones heterónomas; pero en ese contexto, se sigue considerando que hay contrato cuando existe algún grado de libre expresión de los intereses de las partes." 99

Sin embargo, la negociación de los contratantes e incluso el principio de igualdad entre los sujetos se ha visto flexibilizada en las últimas décadas teniendo en cuenta realidades sociales y negociales; y realzando principios como el de buena fe y solidaridad. Reconstruir el principio de solidaridad ajustado al Derecho Contractual de hoy resulta un reto, que nos dirige no necesariamente a alejarnos de la individualidad ni el interés común. Estamos hablando de sí desdeñar el derecho individualista que solo advierte la voluntad del más fuerte en la relación obligatoria, sustituyéndolo por un derecho contractual solidarista que logra un equilibrio, pero tiene en cuenta la situación real de las personas y el amparo de los vulnerables, evitando con ello la preeminencia desproporcionada y el aprovechamiento.

Una mirada al Código Civil Brasileño nos advierte sobre el tema cuando señala en su artículo $421^{100}$ cómo el ejercicio de la libertad de contratar debe estar dentro de los

98 DIEZ PICAZO Y PONCE DE LEÓN, Luis "Contrato y Libertad Contractual”, Revista de Derecho, THEMIS, No. 49, 2004, en http://revistas.pucp.edu.pe, consultado el 19 de mayo de 2017, p.7.

99 Herrera Marisa, Caramelo Gustavo y PICASSO Sebastián (directores), "Código Civil y Comercial de la Nación Comentado", Tomo 3, Libro Tercero, INFOJUS, Buenos Aires, 20I5, p. 340

100 El Código Civil de Brasil establece artículo 42I: "A liberdade de contratar será exercida em razão e nos limites da função social do contrato." Legislacao. 
límites impuestos por su función social, y aunque no han sido pocas las críticas al respecto, su esencia está dirigida a la realidad social y a las consecuencias de los contratos. Lo que se busca es convenir garantías individuales con exigencias de grupos sociales y sujetos vulnerables, donde se protege de abusos, y no se llega a fines utilitarios. Es por ello que la concepción de los contratos en respeto de la libertad contractual, debe estar en alerta ante intereses de los más débiles y con ello intereses sociales. La Convención Americana de Derechos Humanos estipula que toda persona tiene derecho al uso y goce de sus bienes; no obstante, la ley puede subordinar tal uso y goce al interés social. ${ }^{101}$

Al referirse a la autonomía de la voluntad, la contratación actual y el nuevo Código Civil Argentino, Mariano GALGIARDO señala: "no parece necesario destacar que no todo lo que pueda resultar útil y funcional para las partes ha de entenderse permitido sin limitación. Y así como el artículo I197 del Código de Vélez decía "las convenciones hechas en los contratos forman para las partes una regla a la cual deben someterse como la ley misma", tal precepto tiene su correlato en el artículo 958 CCCN: "Libertad de contratación. Las partes son libres para celebrar un contrato y determinar su contenido, dentro de los límites impuestos por la ley, el orden público, la moral y las buenas costumbres". ${ }^{102}$

Pensar en reformular nuestra ley civil sustantiva teniendo en cuenta sujetos más débiles en el ámbito contractual, y al mismo tiempo dar amplio margen a la autonomía, nos conlleva a una revisión de las transformaciones propuestas en materia doctrinal y jurisprudencial en los últimos 20 años. Debemos resistematizar el Derecho Privado de manera que conciba un sistema nuevo que tenga en cuenta fenómenos múltiples como la globalización del derecho, su constitucionalización y la influencia ineludible de los derechos humanos, para así desbordar un Derecho Privado en estrecha vinculación con la realidad y exigencias imperantes.

\section{Libertad Contractual y contratación atípica}

No sería apriorístico señalar que la libertad contractual constituye la fuente de los contratos atípicos, ya que de manera general la misma se fundamenta en que los sujetos puedan celebrar toda clase de contratos. Esta libertad en sede contractual está hermanada con la autonomía privada, la cual constituye un verdadero poder de regulación reconocido a los sujetos, que contiene no solo los contratos atípicos, sino también los típicos. La atipicidad teniendo en cuenta que la propia ley admite que las partes puedan establecer lo que sus intereses estimen según el tráfico jurídico; mientras que en la tipicidad se manifiesta la autonomía en que las partes pueden añadir cláusulas que suplan vacíos de la normativa. "Es que la autonomía privada no es expresión de una

planalto.gov.br/legislacao.nsf/viw_Identificacao/leil 04062002?Opendocument, consultado el 22 de abril del 2004

101 Víd. artículo 21 de la "Convención Americana de Derechos Humanos (Pacto de San José)", en www.oas.org, consultado el 10 de mayo de 2017.

102Galgiardo Mariano, "Moderna contratación. A propósito del Código Civil y Comercial de la Nación", en Revista del Notariado, 922 octubre -diciembre de 2015, versión digital, consultado 8 de junio de 2017. 
mera facultad, sino la manifestación del poder de crear, dentro de los límites establecidos por la ley, $y$ es en la esfera de los intereses privados donde aquella actúa primordialmente. ${ }^{103}$

La libertad de contratación está compuesta por una red de derechos, los cuales de alguna manera se identifican primeramente con la libertad para contratar o no contratar, libertad para decidir el sujeto con el cual negociar o no y la libertad para preferir el objeto del contrato y conformarlo internamente. Todo ello se puede traducir además en la posibilidad de crear nuevos tipos y armonizar los ya existentes, así como la autonomía para convenir las formas que los sujetos aprecien.

$Y$ he aquí donde se manifiestan las mayores libertades en materia de derechos, cuando los sujetos prevén un negocio jurídico de conformidad con sus intereses, claro está dentro de determinados límites, pero creando sus relaciones jurídicas, correspondiendo a sus propósitos prácticos, no hay manera en que personas encuentren mayor independencia que en esto. DIEZ PICAZO, asume un valor tal a la misma que señala:

"Aunque la pregunta tiene que quedar siempre abierta, mi opinión personal es que la libertad contractual presenta un fuerte anclaje en la Constitución. Ante todo, me parece que el reconocimiento de la dignidad de la persona y del libre desarrollo de la personalidad impone la referida libertad, porque sólo se reconoce la dignidad de la persona si se permite autorregular su marco de intereses." 104

En este sentido resulta interesante la Constitución de la Nación Argentina cuyo artículo 19 regula que ningún individuo puede ser privado de lo que la ley no prohíbe, ni obligado a hacer lo que ella no manda, dando al traste con la libertad en sentido amplio, la cual incluye la posibilidad de autorregular contenidos negociales.

Esta libertad incluso viene a suplir las deficiencias normativas ante el avance de la sociedad y de las relaciones económicas, desde la aparición de la tecnología que trae consigo una contratación novedosa, con cambios de paradigma y de la concepción contractual, hasta el expansionismo del mercado que trae consigo nuevos esquemas negociales que no se ajustan a las formas típicas consagradas en los ordenamientos jurídicos.

"El Derecho reconoce que los tipos legislados no pueden agotar las posibilidades de las partes cuando se hallan en el mercado; reina, por tanto, en el Derecho de los Contratos la libertad tipológica. En tal sentido, esta libertad no solo sirve a la economía, al movimiento de la riqueza y a la circulación, sino que permite disimular la forzosa imperfección de la obra legislativa que, confrontada con las particulares necesidades de las partes y dentro de un mundo tecnológico sorprendente, imprevisible y extremadamente veloz, resulta inevitablemente incompleta."105

\footnotetext{
103 FERRI, Luigi, “La autonomía privada”, Granada, Comares, 200I, p.7.

104 DIEZ PICAZO, Luis "Contrato y Libertad Contractual”, op.cit. p. 12.

105 Dispone el art. 1255 del Código Civil Español: "Los contratantes pueden establecer los pactos, cláusulas y condiciones que tengan por conveniente, siempre que no sean contrarios a las leyes, a la moral, ni al orden público".
} 
Ahora bien, múltiples derroteros nos encontramos ante esta libertad, que por una parte complace a los sujetos, pero por otra los coloca ante cuestionamientos como el saber qué normas y régimen le será aplicable a su negocio, sobre todo ante insuficiencias normativas y la ausencia de manifestaciones de los contratantes.

La libertad de contratación se trata de un principio básico, que surge de diversas normas, y que varios ordenamientos jurídicos la reconocen, en estrecha relación con el reconocimiento de los contratos atípicos e innominados y su sujeción a la norma imperativa. Para hacer referencia a la misma se hace indispensable indagar en los caracteres de este tipo de contratación y hacia donde se dirigen los contratos más modernos y sus tendencias de la mano de los retos.

\section{La interpretación, el solidarismo y la tipicidad social. Incidencias para los contratos atípicos y sus retos}

En relación con la disciplina normativa del contrato atípico, cabe destacar que deben atenderse -dada su única naturaleza- las cláusulas contractuales ajustadas por las partes contratantes, siempre y cuando, claro está, ellas no sean contrarias a disposiciones normativas o de orden público. Asimismo, les son aplicables tanto las normas generales previstas en el ordenamiento como comunes para todas las obligaciones y contratos, como las originadas en los usos y costumbres cotidianas; $y$, finalmente, mediante un proceso de autointegración, los del contrato típico con el que guarde alguna semejanza relevante. Ese proceso, aunque se muestra fácilmente, requiere de una pericia interpretativa importante y de un conocimiento sistémico del ordenamiento jurídico civil en general. Al respecto, primeramente se deben tener en cuenta los métodos de interpretación aplicables a cualquier actividad hermenéutica para los textos normativos. Sobre la interpretación normativa analizando el Derecho Comparado, nos ilustran algunos Códigos Civiles sobre una interpretación que debe realizarse al pie de la letra, según sentido común de las palabras, teniendo en cuenta el contexto en el que se inserta. Entre ellos encontramos el Código Italiano, Código Civil Español y el colombiano. Una excepción la formula el Código de Portugal que obliga a los jueces a no conformarse solo con la normativa, sino que pueden "componer" o "reformular" el sentido del legislador, pero con la particularidad de precisar el intérprete la creación entre la intencionalidad y el texto. No le está permitido atribuir al legislador una intención que no encuentre ninguna correspondencia en el texto. ${ }^{106}$ El cómo interpretemos las normas nos conduce a la admisión de contratos atípicos determinados o no, así como a la disciplina que se ajusta. El profesor GUASTINI representante de la doctrina italiana refiere: “...casi todos los códigos, sin embargo, prevén también otros métodos de interpretación. Muchos de ellos -por ejemplo, el italiano, el austriaco, el español, etc. - establecen que las leyes deben ser interpretadas también según la intención o los fines del legislador. No queda clara, sin embargo, la relación de preferencia entre los dos métodos, que claramente pueden conducir a conclusiones diferentes: cada vez que el significado literal y el intencional son (o parecen) distintos, ambos resultan admisibles, y no existe ningún criterio establecido para elegir entre los dos." 107

La interpretación de los contratos atípicos y la disciplina aplicable implican un reto a tener en cuenta ante toda situación, y resulta incuestionable que las reglas de

106 GUASTINI, Riccardo, "Interpretación y construcción jurídica”, Revista ISONOMÍA, No.43, octubre 20I5, p.II-48, p.30.

107 lbídem. 
interpretación contenidas en el Código pueden resultarnos de extrema utilidad. ${ }^{108}$ Son varias las teorías que se han formulado respecto al supuesto contractual atípico ${ }^{109}$ que contiene elementos de dos o más esquemas contractuales típicos, lo que da lugar a los llamados contratos mixtos o complejos. La teoría de la absorción, la de la combinación o de la analogía, han sido estudiadas al respecto, sin embargo, cada una de ellas ha sido criticada en mayor o menor medida toda vez que la adopción de una u otra teoría se corresponderá con cada caso en concreto, a la vista de lo conveniente para cada uno de los sujetos de forma determinada.

Sin embargo, debemos tener en cuenta otros particulares que no se regulan de manera expresa en el Código pero imprescindibles para su interpretación, como el respeto a la finalidad del contrato, la función que las partes le atribuyeron al celebrarlo, la causa presente al momento de su concertación, la composición de obligaciones presentes y que nos llevan al objeto del mismo, todo lo cual nos ayudará a encontrar la solución al problema del régimen jurídico e interpretación del contrato atípico.

Existen autores que añaden a esta lista los usos y costumbres para la interpretación, acotando que "en materia de contratos de tipicidad social, tienen especial relevancia los usos, salvo que se trate de costumbre contra legem, pues en este caso, aun cuando se trate de leyes supletorias, no podrán ser abrogadas por los usos y costumbres. Por consiguiente, los usos y costumbres solo tendrán virtualidad legal cuando no colisionen con la ley, aun cuando esta sea dispositiva. Conviene enfatizar que los usos y costumbres no prevalecen sobre las normas generales supletorias en materia de contratos y obligaciones. Una interpretación en otro sentido es inadmisible, pues olvida que el contrato no es solo un convenio patrimonial entre las partes; el contrato es el texto contractual más el contexto legal gracias al cual tiene vigencia."/10

Por otra parte también debemos tener en cuenta el objeto del contrato atípico que se hace referencia y hasta a los sujetos. Su interpretación va a observar particulares ineludibles, tal es el caso de los contratos atípicos de consumo, cuya interpretación va a ser realizada en el sentido más favorable al consumidor, y asimismo con los contratos atípicos donde en una de las partes tenemos a un sujeto vulnerable -ya sea que presente una discapacidad o sea un adulto mayor- siempre analizando el objeto y esencia del acuerdo de voluntades.

Cuando hacemos referencia a estas concepciones, hay que incursionar - sin ánimo de profundizar en el tema- en doctrinas un poco peliagudas como el solidarismo contractual y el denominado Derecho Social. La primera de ella tuvo sus inicios en Francia a fines del siglo XIX en contradicción con el extremismo de los defensores de la autonomía de la voluntad, que buscaba establecer un cierto equilibrio en los contratos, de manera que se tuvieran en cuenta los intereses del otro sujeto, conviniendo los mandatos tradicionales de estabilidad, seguridad jurídica, entre otros. Esta doctrina para nada desecha la autonomía, pero busca un balance basado en la colaboración, indudablemente

108 El artículo 52 del Código Civil Cubano al referirse a la interpretación contractual señala: "Cuando los términos de una manifestación de voluntad no son suficientemente claros, deben ser interpretados teniendo en cuenta la voluntad presumible del que la emitió, la significación generalmente aceptada de las palabras y las demás circunstancias concurrentes".

109 Vid. OJeDA ROdRíGueZ, Nancy et al, "Derecho de Contratos...”, op.cit., pp. I26-I 27.

110 AGUIRRE MONTENEGRO, Jorge, "Los contratos atípicos"..., op. cit. 
tendrá la posibilidad el sujeto de elegir cómo y con quién contratar, pero situando los intereses del otro en el centro.

El Derecho Social, bien ligado a este nuevo orden contractual, viene apoyado por solidaristas tales como DUGUIT" ${ }^{\prime \prime \prime}$ quien reprocha la finalidad egoísta del derecho subjetivo, según lo entendemos en su forma clásica, y remarca cómo las metas del individualismo están lejos de la realidad. Es una teoría que respalda la protección a los sujetos débiles en la relación contractual, que se puede tener en cuenta para la interpretación del contrato atípico realizada por el juez.

Sobre este análisis añade BERNAL-FANDIÑO: "Un juez solidaristano se limita a la sanción de los comportamientos, tiene una labor más activa, puede reorganizar el contrato. Permite considerar como no escrita una cláusula de responsabilidad abusiva, vigilar que la cláusula resolutoria sea aplicada de buena fe, obligar a la renegociación del contrato según las circunstancias, y hasta revisar el contrato por imprevisión."//2

En los tiempos actuales donde buscamos un nuevo enfoque del Derecho Privado pensado en función del hombre, pero al mismo tiempo respetando sus libertades e intereses, la interpretación y tratamiento de la atipicidad contractual debe ser construida de manera que se tome un nuevo criterio de medida, el interés del sujeto en desventaja o que la sociedad interesa proteger. Estamos hablando del análisis de la finalidad del contrato, su causa, en estrecha relación con la protección a los débiles, lo cual debe ser una premisa del Derecho de Personas, extensiva al Derecho Contractual en todos sus ámbitos. Claro está, si esta proposición no está reconocida como principio en materia de contratos típicos, podremos alcanzar muy poco, sin embargo, la mayoría de las convenciones en las que por su esencia participan sujetos vulnerables; están hoy en plena obra de orfebrería, y su construcción e interpretación jurisprudencial debe dirigirse en estos términos.

No podemos desligar la atipicidad contractual de lo típico, de hecho, lo primero, reiterado en el tiempo, en la práctica y teniendo en cuenta las necesidades sociales, conllevan al reconocimiento por la ley de cada uno de los tipos. ${ }^{1 / 3}$ Es por ello que cuando analizamos la tipicidad contractual, es necesario voltear la mirada al mercado, observar sus conflictos y posibles problemas a presentar, los criterios y tratamientos jurisprudenciales en torno a dichos dilemas, para que de alguna manera muestre el cómo disciplinar el contrato. La realización a la inversa, es decir, tipificar una convención

III DUGUIT, Léon, "Las transformaciones generales del derecho privado desde el Código de Napoleón”, Edit. F. Beltrán, Madrid: 1920, p. 23-24, citado por ARRUBLA, Jaime, Contratos mercantiles, Tomo III, Ed. Diké, 2006, p. 69.

112 BERNAL- FANDIÑO, Mariana, "El solidarismo contractual”, Revista Vniversitas. Bogotá Nº I I4: 15-30, julio-diciembre de 2007, p. 18.

113 Sobre esto añade MOISSET DE ESPANÉS: "Estrictamente se trata de contratos atípicos, pero las costumbres imperantes en una época y lugar determinado los dotan de cierta "tipicidad", lo que suele conducir -con alguna frecuencia- a que el legislador termine ocupándose de ellos y dotándoles de un régimen legislativo especial, momento en el cual esos contratos, originariamente atípicos, se convierten en contratos típicos, como ha sucedido por ejemplo en nuestro país, con el contrato de "maquila", y el contrato de "leasing".'MOISSET DE ESPANÉS, Luis, "Contratos atípicos en la doctrina y jurisprudencia alemanas", Comunicación enviada al Congreso Internacional de Culturas y sistemas jurídicos comparados, organizado por el Instituto de Investigaciones jurídicas de UNAM, México D.F, febrero de 2004. 
determinada para luego ver sus implicaciones, devendría fallida. La realidad donde se implementa es de vital importancia, no importa si ya ordenamientos foráneos lo hayan utilizado, nada reemplaza la experiencia directa de los sujetos con el contrato.

Algunos ordenamientos nos ilustran al respecto como el caso del Perú, donde se reguló el contrato de tiempo compartido, mediante el Decreto Legislativo No. 706 de 199I, en tiempos donde recién surgía este tipo.

En palabras de AGUIRRE MONTENEGRO: "esta norma fue una pura y simple importación, pero ni siquiera fue la copia de una ley en concreto, fue la plasmación legislativa de elucubraciones doctrinarias que aparecían en esa época sobre la figura. Aquellos legisladores se quisieron adelantar; no entendieron la lógica del desarrollo de las tendencias contractuales y del proceso de su tipificación. El resultado fue una norma preñada de incongruencias e inconsistencias, que no respondía al estado de los negocios turísticos en el Perú. Desde esa fecha hasta hoy han pasado más de 20 años, y solo ha habido dos experiencias de tiempo compartido. Ambas fracasaron." 14

Es por ello que los contratos atípicos deben ser estudiados con detenimiento, pues algunos de ellos merecen un tratamiento legislativo, mientras que otros, pueden subsistir perfectamente bajo el régimen de la atipicidad, concibiéndose como aquellos que teniendo o no una denominación especial carece de una reglamentación particular y específica. ${ }^{115}$

$Y$ es importante en este sentido no confundir tipicidad con nominalismo, pues constituyen dos fenómenos diferentes, desde el momento que un contrato puede tener un nombre reconocido por la ley pero no estar regulado, de hecho, que un contrato sea nominado no aporta utilidad práctica, su trascendencia está en la tipicidad, que implica como se ha analizado, la regulación de figuras contractuales de primer o segundo orden mediante la ley. Para las figuras contractuales, los contratos innominados serán aquellos que no tienen un nombre reconocido. ${ }^{116}$

Al enfrentarnos a un contrato atípico, el Código Civil Cubano solo reconoce su existencia y validez a partir de los artículos 314 y 315 , los cuales nos conducen a regirnos por las normas de los contratos más afines y por los preceptos y principios generales del Código. Regulación que no fue para nada exclusiva de nuestro ámbito, ya que otros ordenamientos también se ciñeron a regulaciones semejantes como el artículo 670 del Código Civil Paraguayo que establece que los contratos innominados se regirán por las disposiciones relativas a los nominados con los que tuvieren más analogía.

114AGUIRRE MONTENEGRO, Jorge, "Los contratos atípicos" en, lawiuris.wordpress.com, consultado el 25 de mayo de 2017.

115 Vid. GUTIÉRREZ Y GONZÁLEZ, Ernesto. "Derecho de las Obligaciones”, 5a. edición, Editorial Cajica, S. A. Puebla, 1984, p. 188.

116 "Interesante resulta el razonamiento de OJEDA RODRÍGUEZ cuando señala: "Referirnos a contratos innominados puede ser un error desde el momento que en la práctica suelen tener denominación, aunque no de carácter legal, v. gr.: el contrato estimatorio, el contrato de espectáculo, entre otros. El punto esencial está en si tienen o no regulación expresa y es por esta razón que la doctrina moderna los califica en contratos típicos o atípicos, para ser más precisos y destacar que lo importante es si están tipificados o no en el ordenamiento jurídico, es decir, si tienen o no una regulación expresa." OJEDA RODRÍGUEZ, Nancy et al, "Derecho de Contratos, Tomo I, Teoría General del Contrato", La Habana, 200I, p.I 22. 
Un poco más explícito el nuevo Código Civil y Comercial de la Nación Argentina, se inclinó por mantener la tradición romanista de la clasificación nominativa de los contratos, señalando en su artículo 970 los contratos nominados e innominados. Los contratos son nominados e innominados según la ley los regule especialmente o no. Los contratos innominados están regidos, en el siguiente orden, por: la voluntad de las partes; las normas generales sobre contratos y obligaciones; los usos y prácticas del lugar de celebración; las disposiciones correspondientes a los contratos nominados afines que son compatibles y se adecuan a su finalidad.

\section{La contratación y la protección a los sujetos vulnerables}

Ya conocida en la doctrina resulta la posibilidad de existencia de tipicidad legal o social, donde la última se identifica con que ciertos contratos tienen vida con determinados caracteres en la realidad social, antes de tener reflejo en el ámbito legislativo ${ }^{117}$. En los últimos tiempos, nuestras realidades han estado preñadas de preocupaciones en torno al aumento del envejecimiento poblacional y con ello las discapacidades. El Derecho de Personas ha dado una respuesta a ello, no reflejada aun en la mayoría de las legislaciones, sin embargo la correlativa protección patrimonial ha quedado rezagada. Las nuevas ideas en el ámbito contractual se han diseñado desde lo atípico, con los grandes aportes de la jurisprudencia y doctrina al respecto, colocando al hombre una vez más en el centro del Derecho Contractual, y tendiendo así a su humanización.

Al indagar en la humanización del Derecho Privado, advierte Luis CESARINI "En la axiología del derecho privado, el valor humanidad aparece como un valor, sin embargo nunca se le dio un rol decisivo en las filas del ordenamiento positivo privado, sino que por el contrario se le asignó un valor difuso u opaco. Esto se debe a que el derecho privado se dedicó, fundamentalmente y en forma primigenia, a los valores relacionados con el hombre en su concepción liberal. Esto es, los valores relacionados con la propiedad individual, la voluntad como fuente vital en la celebración de actos jurídicos y la regulación de la libertad de contratación."|18

Ahora le cedemos paso a los sujetos contratantes y miramos además su condición fáctica en la que se sitúan; tanto como se comenzó el interés por el consumidor o usuario, ahora determinadas convenciones se centran en la protección patrimonial y personal a los sujetos vulnerables. El Derecho Privado se halla en un tiempo de profundización en la humanización de sus normativas, y ello debe ser reflejo en todo proceso de mirada al Código Civil.

A pesar de que no contamos en el ámbito patrio con datos estadísticos confiables respecto a la utilización de los negocios atípicos, indudablemente la labor notarial

117 “Antes de llegar a la tipificación legal puede darse la tipificación social de la figura del contrato a través de las propuestas doctrinarias o jurisprudenciales; son contratos que no están regulados por la norma pero, por su contenido adquieren características o denominaciones que le van dando individualidad, como consecuencia de su aplicación reiterada, v. gr.: contrato de factoring, el contrato de mediación, el contrato de franquicia, entre otros." Vid. OJEDA RODRíGUEZ, Nancy et al, "Derecho de Contratos...", op.cit., p.I23.

118 CeSERANI, Luis, "La humanización del derecho privado", Directorio de Abogados, La Ley, Thomson Reuters, www.dab.com.ar, consultado el 20 de mayo de 2017. 
desarrollada en Cuba nos conduce a pensar que no es abundante su utilización, toda vez que los sujetos prefieren ajustarse a los negocios reconocidos por la norma jurídica civil - mercantil. Sin embargo, encontramos que bajo la sombra de negocios testamentarios o donaciones, existe el interés de determinados sujetos en transmitir sus bienes a cambio de cuidados y asistencia. Son aquellos que quieren disponer de su patrimonio considerable $\circ$ no- $y$ no quieren tenerlo inmovilizado, sin embargo, tiene desconocimiento acerca de las instituciones que pueden aplicarse, no cuentan con un correcto asesoramiento de las opciones existentes y dependen de otros (que en ocasiones no quieren atenderlos), o de los exiguos recursos del Estado cuando de utilizar tales bienes podrían ver mejorada su calidad de vida y ello a partir de las rentas resultantes de su patrimonio.

Por otra parte nos encontramos ante la aspiración de un financiamiento privado de la dependencia, donde a través del contrato, puesto en uso como mecanismo de autoprotección, se brinde solución a los problemas derivados del envejecimiento y la imposibilidad de gestionar autónomamente los propios bienes, problemas que pueden derivar de la edad pero también de discapacidades intelectuales. Ante estos supuestos se desatan obligaciones y derechos; cuestiones a interpretar por el juez y abordar por el notario, que de alguna manera contribuirá a la construcción de contratos cuando se confíe en su persona el asesoramiento de estas conjunciones de voluntades.

El Código Civil de los cubanos de 1987 nada refiere respecto a contratos donde intevengan este tipo de sujetos, el legislador para nada previó la importancia de esa protección. Sin embargo, la atipicidad contractual si fue reconocida como abordamos con anterioridad y a ella se ha de acoger los sujetos. La interpretación proteccionista será realizada por el juez, quien en caso de incumplimiento de contratos de este tipo, deberá tener de una mano como regla interpretativa, la protección de los sujetos por su condición de vulnerabilidad en el contrato, y de la otra mano, instrumentos de Derechos Humanos como las Convención sobre los Derechos de las Personas con discapacidad de 2006, aplicables en todas los ámbitos, incluyendo la arena contractual.

\section{I El mandato de protección futura}

En este sentido se han construido por la doctrina y legislaciones europeas contratos que demandaron en algunas ocasiones cambios en las normas para su concesión en la práctica proteccionista. El mandato de protección futura, fue una solución negocial y privada ofrecida a los sujetos en previsión de su incapacidad, brindándoles oportunidades para disponer respecto a su persona, cuando ya no puedan valerse por sí mismas.

Autores como GALLEGO DOMÍNGUEZ lo definen como "aquella figura de protección jurídica contractual que permite a una persona con capacidad suficiente organizar su propia protección para un momento futuro en que no esté ya en condiciones de expresar y formar su voluntad. Mediante esta figura un sujeto con capacidad suficiente otorga a uno o varios mandatarios su representación y la gestión de sus asuntos patrimoniales y/o la protección de su persona para el caso en que por razones fisicas o psíquicas que le impidan la declaración de su voluntad, no pueda atender por sí sola a sus intereses, evitando de esta manera el establecimiento de una medida de protección jurídica judicial."/19

119 GALLEGO DOMíNGUEZ, Ignacio: "Consideraciones sobre el mandato de protección futura en el Derecho Francés", en José PÉREZ DE VARGA MUÑOZ, La encrucijada de la incapacitación y la 
Resulta un negocio que no se extingue por incapacidad ni incapacitación; deriva en un contrato que le permite a una persona de la confianza del mandante continuar gestionando los asuntos en la forma que aquel le hubiera encomendado. Puede operar tanto en la esfera personal como en la patrimonial, y dentro de esta puede abarcar una gestión de alcance general o referirse a uno o varios asuntos concretos. El mandato emana de un negocio jurídico contractual, que no requiere de declaración judicial de incapacidad, haciéndolo una figura única en el ordenamiento.

Ahora bien, en torno al fin de la vida y a la calidad de la misma, no resulta tarea fácil dotar de contenido a un contrato, más aun cuando el contrato debe ser una traducción precisa, acabada y fiel de la voluntad, incrementándose cuando resulta la expresión volitiva de personas vulnerables. En principio podemos afirmar que el contenido de este tipo será, al igual que en el mandato tradicional, el que el mandante disponga, sin embargo, es más complejo el asunto cuando se trata de condiciones de la limitación de la vida o el cese de tratamientos médicos, sobre todo cuando existe contradicción con principios bioéticos o derechos inherentes a la personalidad como el derecho a la vida, a la integridad física, entre otros.

En relación al mandato de protección futura, el Código Civil nos cercena cualquier posibilidad cuando establece en su articulado 409 apartado c), como el mandato se extingue por la incapacidad del mandante o mandatario, siendo ello la causa $y$ fundamento de la figura. Así mismo con varios mecanismos de autoprotección los cuales no pueden hacer uso las personas dependientes, lo cual en futura reforma legislativa debe ser revisado. Una norma que reconociera este negocio jurídico contribuiría a remediar cuestiones como que una persona casada tenga que constituir el organismo tutelar, cuando es más natural que sea el cónyuge que tiene obligación de ayuda respecto al otro quien se ocupe de su esposo ahora devenido incapaz, administrando sus bienes sin más; valorándose en todo caso, la intervención del juez como garantía; todo ello precisamente porque así lo quiere el mandante.

\subsection{El contrato de alimentos. Nuevas perspectivas para la realidad cubana}

Otros negocios jurídicos de protección tales como la renta vitalicia, el contrato de vitalicio y el contrato de alimentos, se han venido analizando como alternativas patrimoniales protectoras para las personas de referencia. La diferencia esencial en cada uno de estos casos viene determinada por su causa, ya que en el caso de la renta los fines pueden ser muy diversos, entre los cuales puede ser que el rentista asegure su subsistencia, pero la renta vitalicia no está llevada a una permanente tendencia a cubrir una necesidad de la vida, no se subordina -como si ocurre en el contrato de alimentosa un permanente estado de necesidad.

El contrato de alimentos deviene en un mecanismo alternativo a la utilización de instituciones tales como la renta vitalicia, el patrimonio protegido, los poderes preventivos, el mandato de protección futura, entre otras, que se han erigido con el propósito de que -desde el ámbito patrimonial- se provea de protección a las personas con discapacidad y a los ancianos. Ahora bien, una de las cuestiones importantes resulta que el contrato de alimentos no se restringe solo a las personas con discapacidad. Es un

discapacidad, editorial La Ley, 201 I, p.292. 
instrumento idóneo para personas que requieran asistencia de un tercero en su vida diaria, como los adultos mayores, tanto para satisfacer las carestías económicas como las afectivas; de ahí sus dos ventajas esenciales: satisfacción de necesidades materiales y asistenciales del alimentista.

Diferentes ordenamientos jurídicos se han encargado de la regulación de figuras afines al contrato de alimentos, aunque los ordenamientos forales españoles han sido los que más han incursionado en estos temas. Lo cierto es que el contrato de alimentos en España germina para atender necesidades de las personas dependientes en general, cuyas atenciones se cuantifican teniendo en cuenta la propia dependencia $y$, al mismo tiempo, para ampliar las posibilidades de protección que solo eran ofrecidas por la renta vitalicia. En Cuba si analizamos la realidad contractual donde interviene un adulto mayor 0 persona con discapacidad, vemos contratos de alimentos con caracteres y propósitos diferentes. No con el nomen iuris asignado, pero en esencia tales, o encubiertos bajo otros tipos negociales. Es cierto que nada obsta su concertación, no existiendo norma prohibitiva en nuestro Derecho Positivo, pero la cotidianidad de los notarios, el desconocimiento de su existencia por los sujetos, y la negativa incorporada a nuestro actuar diario de incursionar en lo atípico o desconocido, exige un reconocimiento normativo del negocio, que señale su contenido y consecuentes efectos notariales y registrales.

Este sería el contrato idóneo para aplicar el solidarismo contractual, la interpretación del juez de manera que adapte la relación a un plano de igualdad. Ahora bien, su atipicidad provoca el inconveniente de que el juez se encuentra ante la encrucijada de desconocer cuáles son las normas aplicables en defecto de pacto.

Cuestiones como estas se suscitaron en España -antes de tipificar el contrato- al contar con la renta vitalicia, la cual Cuba no reconoce. Por una parte una línea jurisprudencial mantenía que el contrato debía regirse por las cláusulas, condiciones que se incorporasen que no fueran contrarias a la ley, el orden público o la moral, siendo subsidiarias las normas generales de las obligaciones y contratos y no se le aplicaban las normas de la renta vitalicia; mientras que otros criterios del Alto Foro Español se inclinaban por además de mantener la inaplicabilidad de las normas de Derecho de contratos y obligaciones en ausencia de pacto, declarar aplicables de forma supletoria lo regulado para el contrato de renta vitalicia o los alimentos ex lege. ${ }^{120}$

Esta determinación indudablemente tenía efectos que trascendía al incumplimiento contractual, ya que de aplicarse las reglas de la renta vitalicia y el obligado a dar alimentos incumplía su prestación, entonces no se admitía la resolución del negocio, toda vez en virtud del artículo 1805 del Código Civil Español la falta de pago de las pensiones vencidas no autorizaba al preceptor de la renta a exigir el rembolso, teniendo solo la posibilidad de reclamar judicialmente la rentas atrasadas y asegurar el pago de la futuras. Mediante la aplicación del otro criterio, entonces, si era posible admitir la Resolución del contrato ante el incumplimiento de la prestación así como el cumplimiento forzoso.

120 Vid. Berenguer Albaladejo, Cristina, "El contrato de alimentos", Tesis doctoral, Universidad de Alicante, Dirigida por Juan Antonio Moreno Martínez, 20I2, p.243, disponible en www.eltallerdigital.com. 
Después de 2003, ya ello no resulta un problema en la sociedad española, en tanto su tipicidad social, permitió un reconocimiento normativo, que beneficiara a estos sujetos. Continua siendo un contrato desde sus orígenes de construcción jurisprudencial, con sus problemáticas en la interpretación por parte del juez que indudablemente trasciende a los intereses de los sujetos.

Ante estas disyuntivas, podríamos preguntarnos en Cuba, ¿Qué régimen podría ser aplicable como contrato atípico de posible incersión en la práctica negocial actual?, ile aplicamos las normas relativas a la obligación alimentaria que reconoce el Código Familiar?; ¿existe algún contrato reconocido en nuestro Código Civil que permita la analogía?; ¿aplicamos el Derecho de Obligaciones y contratos?. Son algunas preguntas a dejar en el tintero, sobre las cuales me inclino a pensar que todo comienzo para dilucidar controversias ante el incumplimiento debe ser aplicando las normas generales de las obligaciones y los contratos.

\section{A modo de cierre}

Los contratos atípicos tienen la característica de ser reconocidos, no en virtud de una normativa, sino como consecuencia de la autonomía privada; es por ello que en el momento de determinación de un régimen aplicable deben tenerse en cuenta los intereses de las partes, sus individualidad y situación de desventaja; y en la interpretación del juez debe estar presente el solidarismo, siendo la validez del contrato tenida en cuenta a la luz de la igualdad, el equilibrio y la seguridad jurídica. La analogía no se debe realizar de forma indiscriminada, alejados de estos presupuestos. La conformación de un régimen sistémico en cada una de las legislaciones para aplicarle a los contratos atípicos, debe estar compuesto por principios, valores y por supuesto la libertad contractual.

Conjugar libertades contractuales, con normas interpretativas y atipicidades, nos lleva a mirar el Derecho Civil de forma sistémica desde sus principios generales hasta el mercado, los actores de hoy en la contratación y los que necesitan incursionar en el mundo del negocio y las relaciones jurídicas obligatorias. En este sentido vislumbra la afirmación de un juez inglés, Sir GEORGE HESSEL, que en la motivación de una sentencia de 1875 afirmó "si hay algo que el interés público reclama más que cualquier cosa, es que los hombres maduros y conscientes deben tener la máxima libertad de contratar y que sus contratos deben ser hechos respetar por los tribunales". ${ }^{21}$

El contrato de alimentos, como un representante de los negocios donde se encuentran presentes sujetos vulnerables, deviene en una alternativa de protección que demanda análisis como contrato atípico en el ámbito cubano y en otros países de la región. Ideal negocio donde aplicar estas teorías solidaristas $y$, por supuesto, vanguardia humanista del Derecho Contractual encontrado con el Derecho de Familia.

En el aniversario de nuestra Código, tenemos mucho que hablar en materia contractual, sobre todo porque es el contrato reflejo de los tiempos y de las más intrínsecas necesidades del hombre de carácter patrimonial y también personal. Comenzar a ver el contrato no solo para adquisiciones patrimoniales sino para lograr protección y asistencia, es un reto para toda reforma legislativa, que aunque no está próxima, pensar

${ }^{221}$ Cit. DieZ PICAZO, Luis, "Libertad Contractual..., op.cit p.II. 
en ella nos consuela ante la confrontación diaria con la realidad. El deseo de la era de la recodificación sigue vivaz y con el auge debido. Las interpretaciones y disciplinas de los contratos atípicos deben ser observadas, para aprovechar sus resultados en el momento que nos llegue la oportunidad de llevarlos a la norma, guía diaria de todo operador jurídico y ciudadano cubano.

\section{BIBLIOGRAFÍA}

\section{Fuentes doctrinales:}

AGUIRRE MONTENEGRO, Jorge, "Los contratos atípicos" en, lawiuris.wordpress.com, consultado el 25 de mayo de 2017; BERNAL- FANDIÑO, Mariana, "El solidarismo contractual”, Revista Vniversitas. Bogotá N I |4: I5-30, julio-diciembre de 2007CESERANI, Luis, "La humanización del derecho privado", Directorio de Abogados, La Ley, Thomson Reuters, www.dab.com.ar, consultado el 20 de mayo de 2017; ARRUBLA, Jaime, Contratos mercantiles, Tomo III, Ed. Diké, 2006, Diez PICAZO y PONCE DE LEÓN, Luis “Contrato y Libertad Contractual", Revista de Derecho, THEMIS, No. 49, 2004, en http://revistas.pucp.edu.pe, consultado el 19 de mayo de 2017; Ferri, Luigi, La autonomía privada, Granada, Comares, 200I; GALlEGo DOMíNGUEZ, Ignacio: "Consideraciones sobre el mandato de protección futura en el Derecho Francés", en José PÉREZ DE VARGA MUÑOZ, La encrucijada de la incapacitación y la discapacidad, editorial La Ley, 20II; GUASTINI, Riccardo: “Interpretación y construcción jurídica”, Revista ISONOMÍA, No.43, octubre 2015; GUTIÉRREZ Y GONZÁLEZ, Ernesto. Derecho de las Obligaciones, 5a. edición, Editorial Cajica, S. A. Puebla, 1984; Herrera Marisa, Caramelo Gustavo Y PICASSO Sebastián (directores), "Código Civil y Comercial de la Nación Comentado", Tomo 3, Libro Tercero, INFOJUS, Buenos Aires, 20I5; HeRRERA OsORIO, Fredy Andrei, "La contratación contemporánea: Ejemplo de la apertura del derecho al contexto" en, Pensamiento Jurídico, No. 33, 2012 en http://revistas.unal.edu.co, consultado 10 de mayo de 2017; OJeDA RodrígueZ, Nancy et al, Derecho de Contratos, Tomo I, Teoría General del Contrato, La Habana, 200I; Ugarte VegA-Centeno, Máximo, Apuntes sobre los Contratos Atípicos o innominados, en "Gestión en el Tercer Milenio, Rev. de Investigación de la Fac. de Ciencias Administrativas, UNMSM”, Vol. I3, № 25, Lima, julio 2010.

\section{Fuentes Legales:}

-Código civil de la República Argentina, Ley n. 340 de 25 de septiembre de 1869, en vigencia el I de enero de 187I, Ed. Depalma, Bs. As., 2000; Código Civil de la República de Cuba, Ley No. 59/1987 de 16 de julio, anotado y concordado por Leonardo B. PÉREZ Gallardo, Ciencias Sociales, La Habana; , 20II; Código Civil del Reino de España de 6 de octubre de 1888, 24a edición, Tecnos, Madrid, 2005; Código Civil de Perú, www.abogadoperu.com, consultado el 3 de mayo de 2017; Convención Internacional sobre Protección de las Personas con Discapacidad, disponible en http://www.un.org/esa/socdev/enable/documents/tccconvs.pdf, consultado I 3 de enero de 2017. 